and perhaps we were wrong in not taking that view years ago-a State examination, either of a practical kind, or also of the nature of a general review examination. I, for one, have no wish to see a King Stork swallow up all our examining bodies, but less of King Log, in the shape of more power to the General Medical Council, is desirable. But that would mean a Medical Bill, and no man who lived through the thirty years' war of the Medical Bills can desire to live to see another. Is it too much to hope that at least the three Conjoint Boards with their flexible machinery will now set themselves in earnest to carry out to the full these behests of the General Medical Council?

Our aim in regard to education should be to promote practical study in all the branches, training the rising youth to observe Nature for themselves, Nature in the laboratories, the dissecting room, the post-mortem room, and at the bedside, and to cultivate the open mind for progress that is sure to be made in our ever-advancing sciences and art. Our aim in regard to the indispensable evil of examinations should be to test such knowledge.

Edinburgh, Nov. 18th, 1893.

\section{THE ALLEGED INCREASE OF INSANITY.}

BY HENRY RAYNER, M.D.

Lecturer on Mental Diseases at St. Thomas's Hospital.

THE great extension of asylums in recent years has made the question of the increase of insanity of interest both to the specialist and the layman, with the result that very widely divergent opinions have been expressed. The Commissioner in Lunacy, in their latest annual reports, have repeatedly suggested that the increase in the number of the recorded insane was more apparent than real. Mr. Noel Humphreys also refused to admit that the then available statistics gave any conclusive evidence of an actual increase in the rate of occurring insanity. More recently Mr. Corbet, in the Fort nightly Review, saw reason to believe that insanity was advancing by leaps and bounds. Dr. Hack Tuke, on the contrary, in treating of the same subject at the annual meeting of the British Medical Association in the present year, arrived at very much the same conclusion as Mr. Humphreys, and Dr. Cobbold has also quite recently endorsed this view

The primary admissions to asylums, if accurate records had heen kept, would at once have solved this question, but unfortunately such statistics as exist are unreliable, so that at present conclusions on the subject can only be drawn indirectly from other facts and figures. The only statistics (for reasons too complex to be briefly stated) which can be relied on for this purpose are those which extend from 1871 to the present date.

The census statistics of insanity for England and Wales analysed in recent articles in this JounNAL have yielded three clear and definite facts : $(a)$ that in the last two decades there has been a progressive diminution in the number of mentally afflicted under the age of 25 years; $(b)$ that there has been an inconsiderable increase between the ages of 25 and $45 ;$ and $(c)$ that practically all the excess of increase has been in persons above the age of 45 years. These results of the recent census, if reliable, would almost limit the question to the inquiry into the reason of this greater excess of cases above the age of 45 .

The tendency of census returns is, by all experience, towards greater accuracy, and although there are doubtless still a certain number of mental cases-especially under the :age of 5-not recorded in the census tables, yet the probability is in favour of this number being less at the late than in the earlier returns. This should have produced a statistical increase, the absence of which emphasises the recorded decrease in the first twenty-five years of life.

A further increase at those ages should have resulted from the great extension of institutional care. Thus, the census of 1871 showed that under the age of 25 there were 4,025 mentally unsound persons in institutions and 10,415 out of them, but in 1891 there were 8,583 in institutions and only ' 7,799 out. The diminution between the ages of 15 and 25 -was from 2.30 per 10,000 of population in 1871 to 2.16 in 1881 and 2.00 in 1891 ; but it is probably even larger than this, since it has occurred in spite of the increase which might have been expected from the greater accuracy of census returns and from the larger survivorship from the doubled numbers in institutions.

The decrease of insanity in the population in the first twenty-five years of life, if satisfactorily proved, would go far to convince those who have actual experience of the insane that this must correspond to a diminution in the total production of mental disease. The tendency to increasing degeneration in the families of the insane, resulting in later generations in mental defect, either congenital or developing in early life, has been pointed out by many observers (Maudsley, Baillarger, etc.), and is a well-established fact. If, therefore, there has been a diminution in the early decades of life, this must correspond to, and be the result of, a lessening of hereditary influences, these being by far the largest factors of causation at these ages, which must operate not only in the early, but also in the later, periods of life.

Hereditary causes, in the tables of the Commissioners in Lunacy, do not, however, bear evidence of any diminution; but it must be remembered that these returns are yearly receiving greater attention, that the means of obtaining information of this kind is steadily increasing, and that at all times the estimates of heredity by different observers have varied as widely as from 30 to 60 per cent.

The lessening of hereditary influences by the restraint in asylums of so much larger a proportion of the insane population is probable, and has long been predicted as a possible result.

The slight excess of recorded insanity between the ages of 25 and 45 is of even greater significance than the diminution in the earlier decades. Mentally afflicted persons àt these ages (and, indeed, at all ages) have been yearly moro and more brought into institutions, from greater confidence in their management, and from the greatly increased comfort therein obtained, but also from the great growth of the urban population (among whom there is much more difficulty in retaining such cases in home life), and, as Dr. Howden, with others, has pointed out, from the changed conditions of industrial life (work being so much more aggregated in factories, etc.), also rendering impossible the home supervision of imbeciles.

These causes, together with an increased keenness, both medical and lay, in the recognition of mental disorder, and a heightened standard of mental fitness from better education, have probably led to more exhaustive registration in the census returns. The influence of these causes is shown hy a table prepared by Mr. Humphreys, from which it appears that the proportion of cases disclosed by the census, but unknown to the Commissioners in Lunacy, is as high as 34 per cent. of the insane population of some agricultural counties, while it falls to 13 per cent. in those having large urban or manufacturing centres.

The asylum population (whatever the causes) has increased since 1871 by about 30,000 , and if the facts relating to increased survivorship under asylum treatment have any cogency, this (survivorship) would by itself account for the small advance in the census numbers of the insane under the age of 45 , from 2.24 per 1,000 of population in 1871 to 2.26 per 10,000 in 1891 , without resorting to any theory of actual increase.

This period of life (from 25 to 45), the period of the greatest activity both physiological and social, the period during which the most important causes of insanity have fullest play, and the period of the incidence of nine-tenths of that extensive disease, general paralysis, would certainly be expected to yield conclusive proof of a definite increase of mental disorder, did any such exist. If, on the contrary. it yields evidence of a doubtful character, the conclusion is inevitable that the patent causes of insanity acting during this period of life are also not in any greatly increased activity.

If heredity is diminished in the early decades, and the most potent direct causes not increased during the most active period of life, what are the new factors that lead to a greater development of insanity after the age of 45 , if there is any such? Is it, indeed, increase, or mere accumulation from greater survivorship and other causes?

That there is a very greatly increased survivorship of persons mentally affected when cared for in institution, and ispecially in the asylums, cannot be doubted. 
Dr. Farr analysed the statistics relative to the death-rate among pauper lunaties, inmates of the metropolitan licensed houses between 1833-9, and found it to be 20.7 per cent. (26.8 males and 16.4 females); this death-rate would obviously not favour accumulation-would, indeed, extinguish the insane population in a few years.

Mr. Noel Humphreys analysed the death-rates for the metropolitan imbecile asylums, finding that their death-rate of 13.34 for 1871-5, fell successively to 8.32 in 1876-80, to 7.73 in 1881-5, and 7.40 in 1886-8. "These asylums," he observes "contained only 1,344 persons at the beginning of 1871 , and 4,919 at the end of 1888 . If the mean death-rate of the first three years had continued, and if the average number resident had been maintained by extra admissions, the number of deaths in these asylums alone would have exceeded the number actually recorded by 3,712 " $\mathrm{He}$ adds: "There is no reason to believe that the death-rate of these imbeciles when in the workhouses was any lower than that which occurred in the earlier years of these institutions."

Mr. Humphreys's analyses of the mortality in the asylums, etc., of England and Wales, prove that the mean annual rate per 1,000 was 103.1 in $1859-68$, 101.7 in 1869-78, and only 95.53 in 1879-88. Dr. Hack Tuke has calculated that if the rate of 103.1 in the earliest period had continued until 1891, there would have been 5,624 fewer patients living at the latter date than was actually the case. Increased survivorship from these data would seem to be sufficient indeed to account for nearly the whole of the excess of recorded cases, but other causes remain to be considered.

The transfer of persons from the pauper to the lunatic class is another reason of the apparent excess in the recorded numbers of the insane. The Governmental grant of $4 \mathrm{~s}$. per head per week to all pauper inmates of asylum came into operation in 1874, and of its influence in this respect there is a general consensus of agreement. In the years following its operation, asylum superintendents were almost unanimous in their yearly reports in complaints of the increased admission of paralysed persons and aged imbeciles, many recording a considerable rise in the average age of the admissions as a consequence. Dr. Campbell, for example, reports that in the admissions to the Carlisle Asylum, the persons aged 70 and upwards were only 2 per cent. prior to 1872 , but in the next decade were 4 per cent., and in the last decade 6 per cent.

If a similar increase of senile admissions obtained throughout the country, in the 130,343 admissions of the first decade and the 152,095 of the second, it would yield an increase in the admissions of 8,589 during the twenty years, and this alone might account for much of the apparent excess of insanity; but to these have to be added a large number of hemiplegic and other paralytics at earlier ages. The question, however, may be raised whether the undoubted increase of senile admissions was due to the $4 \mathrm{~s}$. capitation grant, or to an increased occurrence of senile insanity.

Here, again, personal experience and the annual reports of the asylum superintendents (Dr. Clouston and others) confirm the opinion that it is due rather to the increased certification of dotards and paralysed persons, not previously classed as insane, than to increase of disease. This result would appear to be brought about by the changed conditions of life, already alluded to, rendering the working population less able or wishful to keep out of the workhouses their helpless, aged, or paralysed, and the workhouse authorities having become:more keen in detecting mental enfeeblement since the capitation grant has been established.

The transfer of persons formerly ranked as criminals to the lunatic class is another mode in which the numbers of the insane have been added to in the last twenty years.

An eminent alienist physician, of large experience in prisons, recently expressed the opinion at a public meeting that a not inconsiderable part of the decrease of criminals was due to the fact that many weak-minded persons, formerly classed as criminals, were now relegated to asylums. The statistics in support of this view are, however, not easily available.

The proof of the greater frequency in the occurrence of insanity has been further based on the great advance in the number of admissions to asylums, which have risen from 9,267 in 1871 to 14,764 in 1891 . There are many ways in which this great apparent advance is negatived. One important item is the greater number of relapses from the larger number discharged from asylums; these discharges have increased (in round numbers) from 4,000 in 1871 to 11,000 in 1891. Evidence of this may be found in the Report of the Commissioners of Lunacy for Scotland, 1893, p. 21, in a table giving the asylum history of 1,319 patients first admitted in 1868, which shows that in the twenty years to 1888 these had yielded 496 readmissions, 37.5 per cent. of the original admissions, for the whole period, or 1.875 per cent. annually. This table is a very striking proof of the great advance in admissions (readmissions) which result from any addition to the asylum population, and as this population has increased in England and Wales by about 30,000 in the twenty years, or 1,500 per annum, the calculation based on this Scottish experience may be made that probably a third of the increased admissions may be traced to this cause alone.

If Dr. Campbell's statistics of the increased certification of senile cases are true of the whole country, probably another sixth might be thus accounted for. During this period (1871 to 1891) the number of persons of unsound mind in workhouses and residing with friends has diminished (in round numbers) by 1,000 , and those recorded in the census but not officially known by about 1,800 ; these also must have gone to swell the total admissions to the asylums.

The judicial statistics for 1871 show that 0.26 per cent. of the number of persons committed for trial were found insane, while in 1891 the percentage (on reduced numbers) was 0.46 , corresponding to a distinct increase; but there can be no doubt that the recognition of insanity in those arraigned as criminals is more frequent and prompt than formerly both prior to and after committal for trial or condemnation, and accounts for a considerable addition to the numbers of the insane.

The influence of the capitation grant of 1874 in stimulating admissions was very obvious. In 1871 the rate per 10,000 of the population was 4.067. The advance in 1872 and 1873 was 0.008 and 0.180 ; but in 1874 it was 0.409 ; in 1876 it reached 0.664 , and declined from this point to 0.186 in 1885 , since when it has steadily risen to 1.008 in 1891 . There can be little doubt that the sudden rise in 1874-78 was mainly due to the capitation grant.

An example of its influence may be taken from the admissions of 1883 , which were swollen by 668 pauper imbeciles having been certified to asylums in Lancashire alone in that year.

In addition to these causes of increased asylum admissions there is the probability that the residual insanity undisclosed even by the earlier census returns has been largely drawn upon'and has tended to swell those numbers.

If, again, the possible causes of increase be considered in detail, very little evidence can be found to support the excessive increase theory.

Heredity, the most potent factor, would at least not appear to have expanded; intemperance, the next great cause, if police reports can be relied on, is greatly lessened; while two other important causes, poverty and crime, are considerably diminished ; Dr. Cobbold points out that fevers and post-febrile insanities are now less frequent. The other principal causes operating during the active periods of life do not appear to have materially added to the numbers of the insane at these ages; and, lastly, reasons have been adduced which throw doubt on there being any real excess of senile unsoundness.

The only form of mental disease in which a great development is alleged is general paralysis; but Calmeil, in 1826 , found as large a percentage in the inmates of a French asylum as would be found in many English asylums at the present day. The apparent excess of general paralysis is probably chiefly due to increased care in diagnosis and to such cases being more largely sent to asylums. This form of disease, however, with an average asylum duration of two to three years, would not greatly add to the permanent numbers, except by an increase much beyond that which is claimed for it.

If the influences of civilisation were acting in the direction alleged, a study of the classes of the community ought to produce very important evidence. The statistics of classes, however, would seem to indicate that while there had been a 
large increase of the recorded insane in the pauper class, the private or well-to-do class had undergone diminution both in the admissions and the numbers under care. In 1879 the ratio of private lunatics per 10,000 of population was 2.97, which has fallen by steady annual decreases to 2.61 ; and the admissions of this class have diminished (Dr. Cobbold) in the same progressive manner, from 1.07 per 10,000 in 1882 to 0.92 1892. These facts would be a strong argument against the enormous increase theory, but the facts are so complicated and uncertain that it would be unfair to urge this as a proof of an actual diminution in the occurrence of mental defect in the richer classes, although it certainly negatives the theory of large increase.

If the general or any special causes of insanity, the result of the intensified conditions of civilisation, were in operation, they should produce a steady and progressive development of the numbers of the insane. This, however, is not the case, but the contrary is the fact. The rate of increase, as Dr. Merson has pointed out, has fallen from 512 per million in 1859-69 to 361 in 1869-79, and 212 in 1879-89.

The increase of certificated insanity, on the contrary, has not been steady and progressive, but in waves; a large wave (as previously described) corresponding to the capitation grant in 1874, subsiding in 1885 , eleven years later, to the level of 1872. The wave may be more easily traced in the smaller areas of counties, the manufacturing and urban preceding the agricultural, but is also very distinct in the statistics of Ireland and Scotland, where, as Dr. Clouston has pointed out, its influence was quite as marked as in.England, but occurred a year or two later.

From these facts the conclusions may be drawn that there is no definite evidence of the increased incidence of any special causes of mental disorder, or of the development of new or special forms of disease; that the accumulation of the insane in asylums has been mainly coincident with the operation of the parliamentary capitation grant, and that the rate of accumulation is undergoing a progressively rapid decline.

Further, it seems probable that the increased numbers of the insane in asylums and elsewhere may be accounted for by the greater survivorship in asylums (overriding even a diminished production in the earlier periods of life), by the transfer of paupers and criminals to the lunatic class, and by the increased accuracy of the census returns.

The ultimate conclusion is that the evidence at present available admits of the interpretation that there is no real excess in the amount of occurring insanity, but is even compatible with the possibility of an absolute diminution, which has certainly occurred in the earlier decades of life, and is probable in the well-to-do classes.

\section{THE EMPLOYMENT OF ELECTRIC LIGHTING CURRENTS FOR MEDICAL PURPOSES.}

BY H. LEWIS JONES, M.D.

Medical Officer in charge of the Electrical Department, St. Bartholomew's Hospital.

Wiтн the steady advance of electric lighting both in London and country towns the application of electric lighting currents to medical and surgical purposes is coming more and more into notice. Already many medical men use the current from the mains in the treatment of their patients ; and more would do so were it not for a widespread belief that there is some risk of accidents occurring, though with properly chosen apparatus and with ordinary care there is no danger.

The current supplied by the companies is in some cases an alternating current and in others a continuous one. ${ }^{1}$ The pressure at which it enters houses is usually 100 volts, and, as this is too high for medical purposes, some device must be employed before the current can be applied to a patient. When the supply is an alternating one, it is very easy by means of a transformer to reduce the voltage to any required degree, and then there is no difficulty. A Woakes's or similar transformer enables the operator to obtain the most delicate graduation of the voltage, and it is perfectly safe

1 The St. James and Pall Mall, Westminster, Kensington and Knights bridge, Chelsea, Charing Cross and Strand, and St. Pancras Companies supply a continuous current. The Metropolitan, the London, City of London, and House to House Companies supply an alternating curlent. and easy to handle, and when properly wound it will heat cauteries, light small surgical lamps, or yield an "indaction" current for the testing or treatment of paralysed muscles.

The customary pressure for cauteries is 4 volts, that proper for the electric bath is 6 to 8 , and for applying "induction currents" to patients is 10 to 16 . With the alternating supply the use of a properly graduated transformer ${ }^{2}$ to lower the voltage is in every way better than to use the full pressure of the mains and to choke down the current by means of resistances. On the continuous current systems it is a complicated and expensive matter to reduce the voltage by transforming contrivances, and resistances are therefore more often employed for the purpose of reducing the magnitude of the current. These resistances, however, are not very satisfactory.

Five milliampères from a source of electricity at 100 volts is more unpleasant than the same current from a battery of low voltage, especially at the moment of first contact with the skin; for whatever the magnitude of the interposed resistance may be, the electrodes before contact with the body are at the full potential of 100 volts, and when the contact is made the high pressure expends itself in quickly breaking down the skin resistance, with more pain and shock than when the resistance is gradually overcome by a lower voltage. The drier the skin the greater is the discomfort. When the skin is thoroughly moistened and reddened this effect is much less marked; though practically I have found that infants and young children are far less tolerant of current from a high than from a low voltage source, even if the current be the same in both cases.

Another objection to the use of resistances to reduce the current is that several separate types and sizes are requined for the different applications of the current; a rheostat suitable for a cautery will not do for surgical lamps, nor will one suitable for the latter do for galvanic applications to patients. In the use of electric light mains for heating cauteries, regulation by a rheostat is dangerous, for any accidental fusing of the platinum cautery wire is likely to be followed by the formation of an electric arc at the broken point, an accident which might lead to the most serious consequences. Moreover, the contacts in the handles of the cautery instruments as at present made are apt to give trouble by sparking and burning away.

There is a plan of avoiding these risks by distributing the current along two parallel circuits, one of which carries the cautery, the resistance of the two circuits being so adjusted that the current through the cautery cannot exceed a certain. value. In this way the danger of the formation of an arc is avoided, but the apparatus wastes a large amount of current.

By far the best way of utilising the continuous current supply is to charge accumulators with it in the first place, and then to take out current from the accumulators. This plan requires a smaller outlay in plant and apparatus, and the accumulators being portable the operator is not tied down to one spot as he is by a fixed installation, but ean. carry his charged accumulators to his patient when his patient cannot come to him.

Although accumulators are most unsatisfactory when they are not properly attended to, this is the fault, not of the accumulator itself, but of its treatment. Under proper conditions of recharging a secondary cell behaves very well, though it soon spoils if left uncharged for three or six months at a stretch; such treatment as that will ruin any accumulator.

By means of accumulators the continuous 100 volt electric. lighting current can be made available for medical purposes. at a smaller outlay, and with fewer complications than by any arrangement of resistances. The Lithanode Company make excellent secondary cells which weigh less than 8 ozs. a-piece, and indeed they have cells weighing as little as $2 \frac{1}{2}$ ozs. each, which are perfectly suited for galvanisation of patients, for electrolysis, or for the testing of muscle and nerve and so on.

2 A very good transformer is made by Messrs. Miller and Woods, of 2 , Gray's Inn Road, and is figured in the Electrician for September 29 th, 1893 .

3 The Lithanode and General Electric Company, Limited, 64, Millbank: Street, Westminster, S.W. 